\title{
Updating UK estimates of age, sex and period specific cumulative constant tar cigarette consumption per adult
}

\author{
Barbara A Forey, Peter N Lee, John S Fry
}

\begin{abstract}
Background-In 1993 we presented age and sex specific estimates of cumulative constant tar cigarette consumption (CCTCC) per adult for five year periods to 1986-90. These were derived from annual surveys conducted for the Tobacco Manufacturers' Association (TMA) since 1946, extrapolated back to 1891 for men and to 1921 for women and corrected for the decline in average (machine smoked) tar levels. We now provide estimates for 1991-5.

Methods-TMA surveys having ceased, 1991-5 estimates of manufactured cigarette consumption per adult (MCA) were derived from the General Household Survey (GHS) and corrected for the continuing decline in tar. These estimates were divided by 0.75 (men) and 0.80 (women), based on a comparison of GHS and TMA data for 1971-90, to allow accumulation with the TMA derived estimates prior to 1991.
\end{abstract}

Results-For both sexes the GHS/TMA ratio of MCA varied little by age or five year period, justifying the use of the correction factors when adjusting GHS estimates for 1991-95. TMA estimates were higher than GHS estimates as only TMA sales-corrected their data for understatement of smoking and the surveys differed in questions on handrolled cigarette smoking. The 1991-95 data confirm the continuing decline in CCTCC at all ages in men. Women show a less steep decline for ages 30-64 and an increase for ages 65-84.

Conclusion-The GHS data can validly be used to update the CCTCC estimates. Some reservations about the use of CCTCC are discussed.

(Thorax 1998;53:875-878)

Keywords: cumulative constant tar cigarette consumption; adult; UK

In Thorax in 1990 we presented a study relating trends in cigarette smoking to trends in lung cancer, chronic obstructive lung disease, and emphysema in England and Wales for
1941-85. ${ }^{1}$ To index lifetime cigarette consumption we computed age, sex, and period specific estimates for the UK of cumulative constant tar cigarette consumption (CCTCC) obtained by aggregating annual age and sex specific data on manufactured cigarette consumption per adult, and correcting for the decline since 1965 in tar level measured under standard smoking conditions. The annual data came from surveys conducted since 1946 for the Tobacco Manufacturers' Association (TMA) or its predecessors, ${ }^{23}$ extrapolated back to 1891 for men and to 1921 for women using an age cohort model.

Approached in 1993 by the Lung and Asthma Information Agency (LAIA) for CCTCC figures updated to 1990, we noted an error in the method used to derive them. Although not materially affecting our estimates or conclusions, ${ }^{1}$ we wrote to Thorax to present corrected and updated CCTCC data. ${ }^{4}$ Estimates were tabulated by five year age groups from $15-19$ to $80-84$, and five year periods from $1901-5$ to $1986-90$ for men and from 1926-30 to 1986-90 for women. We also made available full details of the data and methods used. ${ }^{5}$ Updated graphs appeared in an LAIA factsheet.

The LAIA recently approached us again for CCTCC estimates updated to 1995. As the TMA have not conducted any surveys since 1989, we used General Household Survey (GHS) data. Here we describe differences between the TMA and GHS data, explain and justify how we modified our estimation procedure to account for them, and present updated CCTCC estimates.

\section{Methods}

TMA DATA UP TO 1990

Available separately ${ }^{5}$ are (1) estimates of manufactured cigarette consumption per adult per year by age and sex for five year periods from 1941-45 to 1986-90 derived from annual surveys, (2) estimates derived by backward extrapolation to 1891-95 for men and 1921-25 for women, and (3) estimates of manufactured cigarette consumption per adult per year adjusted using tar factors of $1,0.804$, $0.613,0.544,0.477$ and 0.423 , respectively, for 1961-65, 1966-70, 1971-75, 1976-80, 
Table 1 Basic age and sex specific GHS cigarette smoking data used in estimation

\begin{tabular}{|c|c|c|c|c|c|c|c|c|c|c|c|c|c|c|c|}
\hline \multirow[b]{2}{*}{ Sex } & \multirow[b]{2}{*}{ Age } & \multicolumn{14}{|l|}{ Year } \\
\hline & & 1972 & 1973 & 1974 & 1975 & 1976 & 1978 & 1980 & 1982 & 1984 & 1986 & 1988 & 1990 & 1992 & 1994 \\
\hline \multicolumn{16}{|c|}{ Prevalence of cigarette smoking } \\
\hline \multirow[t]{6}{*}{ Men } & $16-19$ & 43 & . & 42 & . & 39 & 35 & 32 & 31 & 29 & 30 & 28 & 28 & 29 & 28 \\
\hline & $20-24$ & 55 & . & 52 & . & 47 & 45 & 44 & 41 & 40 & 41 & 37 & 38 & 39 & 40 \\
\hline & $25-34$ & 56 & . & 56 & . & 48 & 48 & 47 & 40 & 40 & 37 & 37 & 36 & 34 & 34 \\
\hline & $35-49$ & 55 & . & 55 & . & 50 & 48 & 45 & 40 & 39 & 37 & 37 & 34 & 32 & 31 \\
\hline & $50-59$ & 54 & . & 53 & . & 49 & 48 & 47 & 42 & 39 & 35 & 33 & 28 & 28 & 27 \\
\hline & $60+$ & 47 & . & 44 & . & 40 & 38 & 36 & 33 & 30 & 29 & 26 & 24 & 21 & 18 \\
\hline \multirow[t]{6}{*}{ Women } & $16-19$ & 39 & . & 38 & . & 34 & 33 & 32 & 30 & 32 & 30 & 28 & 32 & 25 & 27 \\
\hline & $20-24$ & 48 & . & 44 & . & 45 & 43 & 40 & 40 & 36 & 38 & 37 & 39 & 37 & 38 \\
\hline & $25-34$ & 49 & . & 46 & . & 43 & 42 & 44 & 37 & 36 & 35 & 35 & 34 & 34 & 30 \\
\hline & $35-49$ & 48 & . & 49 & . & 45 & 43 & 43 & 38 & 36 & 34 & 35 & 33 & 30 & 28 \\
\hline & $50-59$ & 47 & . & 48 & . & 46 & 42 & 44 & 40 & 39 & 35 & 34 & 29 & 29 & 26 \\
\hline & $60+$ & 25 & . & 26 & . & 24 & 24 & 24 & 23 & 23 & 22 & 21 & 20 & 19 & 17 \\
\hline \multicolumn{16}{|c|}{ Cigarette consumption per week } \\
\hline \multirow[t]{6}{*}{ Men } & $16-19$ & 102 & . & 110 & . & 106 & 98 & 99 & 87 & 87 & 86 & 84 & 89 & 81 & 71 \\
\hline & $20-24$ & 123 & . & 132 & . & 135 & 122 & 113 & 114 & 107 & 108 & 109 & 110 & 92 & 94 \\
\hline & $25-34$ & 129 & . & 136 & . & 138 & 134 & 135 & 121 & 114 & 110 & 120 & 115 & 100 & 107 \\
\hline & $35-49$ & 132 & . & 138 & . & 141 & 138 & 140 & 137 & 130 & 133 & 136 & 135 & 130 & 126 \\
\hline & $50-59$ & 124 & . & 127 & . & 130 & 137 & 130 & 129 & 126 & 120 & 132 & 121 & 129 & 142 \\
\hline & $60+$ & 96 & . & 100 & . & 108 & 104 & 102 & 109 & 103 & 103 & 102 & 106 & 102 & 99 \\
\hline \multirow[t]{6}{*}{ Women } & $16-19$ & 76 & . & 86 & . & 89 & 90 & 84 & 76 & 80 & 77 & 79 & 80 & 70 & 70 \\
\hline & $20-24$ & 91 & . & 99 & . & 110 & 101 & 102 & 100 & 91 & 85 & 95 & 92 & 88 & 90 \\
\hline & $25-34$ & 97 & . & 108 & . & 109 & 113 & 111 & 109 & 105 & 101 & 103 & 103 & 97 & 97 \\
\hline & $35-49$ & 94 & . & 104 & . & 112 & 109 & 115 & 108 & 107 & 112 & 113 & 106 & 111 & 104 \\
\hline & $50-59$ & 87 & . & 91 & . & 103 & 101 & 105 & 101 & 98 & 99 & 102 & 107 & 105 & 106 \\
\hline & $60+$ & 60 & . & 68 & . & 75 & 79 & 73 & 77 & 80 & 84 & 81 & 81 & 81 & 89 \\
\hline \multicolumn{16}{|c|}{$\%$ mainly hand rolled (among cigarette smokers) } \\
\hline \multirow[t]{7}{*}{ Men } & $16-19$ & 3.2 & 3 & 2 & 3 & . & 4 & 6 & 11 & 7 & 5 & $10^{1}$ & $10^{1}$ & $11^{1}$ & $11^{1}$ \\
\hline & $20-24$ & 5.7 & 6 & 5 & 8 & . & 7 & 8 & 15 & 16 & 13 & & & & \\
\hline & $25-29$ & 10.7 & 10 & 9 & 12 & . & 14 & 15 & 19 & 16 & 14 & $14^{2}$ & $16^{2}$ & $15^{2}$ & $20^{2}$ \\
\hline & $30-34$ & 14.4 & 12 & 12 & 12 & . & 13 & 12 & 24 & 18 & 19 & & & & \\
\hline & $35-49$ & 14.5 & 13 & 16 & 14 & . & 16 & 16 & 22 & 18 & 19 & 20 & 17 & 20 & 23 \\
\hline & $50-59$ & 15.0 & 15 & 16 & 15 & . & 14 & 17 & 24 & 19 & 20 & 21 & 20 & 19 & 22 \\
\hline & $60+$ & 16.5 & 17 & 18 & 20 & . & 18 & 18 & 21 & 19 & 22 & 22 & 26 & 22 & 25 \\
\hline \multirow[t]{7}{*}{ Women } & $16-19$ & 0 & 1 & 0 & 0 & . & 0 & 1 & 2 & 2 & 2 & $1^{1}$ & $2^{1}$ & $3^{1}$ & $3^{1}$ \\
\hline & $20-24$ & 0.6 & 1 & 0 & 0 & . & 1 & 3 & 3 & 4 & 4 & & & & \\
\hline & $25-29$ & 0.5 & 1 & 1 & 0 & . & 1 & 2 & 4 & 3 & 3 & $3^{2}$ & $3^{2}$ & $3^{2}$ & $5^{2}$ \\
\hline & $30-34$ & 1.1 & 1 & 1 & 1 & . & 0 & 1 & 3 & 3 & 2 & & & & \\
\hline & $35-49$ & 0.7 & 1 & 1 & 1 & . & 1 & 1 & 2 & 3 & 2 & 3 & 2 & 3 & 4 \\
\hline & $50-59$ & 1.3 & 1 & 1 & 1 & . & 1 & 1 & 2 & 2 & 2 & 2 & 1 & 1 & 3 \\
\hline & $60+$ & 1.2 & 1 & 2 & 1 & . & 1 & 2 & 3 & 2 & 3 & 2 & 2 & 1 & 3 \\
\hline
\end{tabular}

\footnotetext{
${ }^{1}$ Estimates for age 16-24.
}

${ }^{2}$ Estimates for age $25-34$.

1981-85 and 1986-90, based on sales weighted average tar (SWAT) data calculated by the TMA using results from surveys by the Laboratory of the Government Chemist issued as leaflets by the Health Departments of the United Kingdom. The source ${ }^{5}$ also describes how these tar adjusted estimates were corrected and cumulated to obtain the CCTCC data presented in $1993 .{ }^{4}$

\section{UPDATING CCTCC DATA TO 1995}

CCTCC data for 1991-95 used the same TMA derived estimates of manufactured cigarette consumption per adult per year up to 1990, GHS derived estimates for 1991-95, and a tar factor of 0.358 for 1991-95.

DERIVING ESTIMATES FROM GHS DATA

GHS data were available every other year from 1972, with some data for 1973 and 1975. Averaging data available within each five year period provided estimates from 1971-75 to 1991-95. Data on cigarettes per adult per year (CPA) were estimated by multiplying data on cigarettes per smoker per week by 52 and then by prevalence. Data provided were in age groups such as 16-19, 20-24, 25-34, 35-49, 50-59 and 60+. CPA estimates for age 16-19 were taken as applicable to age 15-19 (assuming 15 year olds did not smoke at all produced estimates markedly lower than TMA). CPA estimates were assumed to be equal in each five year age group within any broader age group in the range 20-59. Using age and sex specific GHS data on the percentages of smokers who smoked mainly plain, mainly filter, or mainly hand rolled cigarettes, CPA estimates were adjusted to estimate manufactured cigarette consumption by excluding those who smoked mainly hand rolled cigarettes.

ADJUSTING GHS ESTIMATES

Manufactured cigarette consumption estimates derived from GHS data were compared with TMA estimates for 1971-75 to 1986-90, TMA data for age $60+$ being estimated from five year age data by age weighting to the UK population. ${ }^{6}$ The ratio of GHS to TMA estimates then provided approximate sex specific factors to correct GHS estimates for 1991-95 when calculating the final CCTCC estimate. For five year age groups within the $60+$ age group CPA estimates were then derived using the same ratio to $60+$ age group estimates as for TMA 1986-90 data.

\section{Results}

Table 1 presents the original GHS data on cigarette smoking prevalence, weekly consumption per smoker, and percentage of mainly handrolled cigarette consumption among cigarette smokers.

Table 2 compares GHS and TMA estimates of manufactured cigarette consumption per 
Table 2 Manufactured cigarette consumption per adult per year. Comparison of TMA and GHS estimates for 1971-90 and adjustment of GHS estimate for 1991-95

\begin{tabular}{|c|c|c|c|c|c|c|c|c|c|c|c|c|c|}
\hline \multirow[b]{2}{*}{ Sex } & \multirow[b]{2}{*}{ Year } & \multirow[b]{2}{*}{ Source } & \multicolumn{10}{|l|}{ Age } & \multirow[b]{2}{*}{ Mean } \\
\hline & & & $15-19$ & $20-24$ & $25-29$ & $30-34$ & $35-39$ & $40-44$ & $45-49$ & $50-54$ & $55-59$ & $60+$ & \\
\hline \multirow[t]{14}{*}{ Men } & \multirow[t]{3}{*}{$1971-75$} & GHS & 2281 & 3354 & 3479 & 3350 & 3272 & 3272 & 3272 & 2950 & 2950 & 1918 & \\
\hline & & TMA & 2664 & 4520 & 4310 & 4310 & 4440 & 4200 & 4570 & 4260 & 3570 & 2629 & \\
\hline & & Ratio & 0.86 & 0.74 & 0.81 & 0.78 & 0.74 & 0.78 & 0.72 & 0.69 & 0.83 & 0.73 & 0.77 \\
\hline & \multirow[t]{3}{*}{$1976-80$} & GHS & 1782 & 2690 & 2904 & 2948 & 2933 & 2933 & 2933 & 2798 & 2798 & 1683 & \\
\hline & & TMA & 2352 & 3850 & 3790 & 3840 & 3780 & 3810 & 3670 & 3930 & 3200 & 2221 & \\
\hline & & Ratio & 0.76 & 0.70 & 0.77 & 0.77 & 0.78 & 0.77 & 0.80 & 0.71 & 0.87 & 0.76 & 0.77 \\
\hline & \multirow[t]{3}{*}{$1981-85$} & GHS & 1234 & 1968 & 2015 & 1929 & 2192 & 2192 & 2192 & 2105 & 2105 & 1390 & \\
\hline & & TMA & 1824 & 2880 & 2980 & 2920 & 3080 & 2870 & 2890 & 2680 & 2700 & 1648 & \\
\hline & & Ratio & 0.68 & 0.68 & 0.68 & 0.66 & 0.71 & 0.76 & 0.76 & 0.79 & 0.78 & 0.84 & 0.73 \\
\hline & \multirow[t]{3}{*}{ 1986-90 } & GHS & 1222 & 1906 & 1871 & 1836 & 2049 & 2049 & 2049 & 1649 & 1649 & 1089 & \\
\hline & & TMA & 1840 & 2850 & 2667 & 2850 & 2733 & 2467 & 2717 & 2400 & 2083 & 1515 & \\
\hline & & Ratio & 0.66 & 0.67 & 0.70 & 0.64 & 0.75 & 0.83 & 0.75 & 0.69 & 0.79 & 0.72 & 0.72 \\
\hline & \multirow[t]{2}{*}{ 1991-95 } & GHS & 1071 & 1662 & 1508 & 1508 & 1647 & 1647 & 1647 & 1538 & 1538 & 782 & \\
\hline & & Adjusted $^{1}$ & 1428 & 2216 & 2011 & 2011 & 2196 & 2196 & 2196 & 2051 & 2051 & $1043^{2}$ & \\
\hline \multirow[t]{14}{*}{ Women } & \multirow[t]{3}{*}{$1971-75$} & GHS & 1620 & 2261 & 2508 & 2501 & 2477 & 2477 & 2477 & 2174 & 2174 & 836 & \\
\hline & & TMA & 2040 & 3110 & 3090 & 3060 & 2920 & 3240 & 3430 & 2950 & 2340 & 1090 & \\
\hline & & Ratio & 0.79 & 0.73 & 0.81 & 0.82 & 0.85 & 0.76 & 0.72 & 0.74 & 0.93 & 0.77 & 0.79 \\
\hline & \multirow[t]{3}{*}{$1976-80$} & GHS & 1501 & 2289 & 2456 & 2465 & 2518 & 2518 & 2518 & 2334 & 2334 & 932 & \\
\hline & & TMA & 1928 & 3100 & 2960 & 3130 & 3200 & 2890 & 3140 & 3190 & 2700 & 1177 & \\
\hline & & Ratio & 0.78 & 0.74 & 0.83 & 0.79 & 0.79 & 0.87 & 0.80 & 0.73 & 0.86 & 0.79 & 0.80 \\
\hline & \multirow[t]{3}{*}{$1981-85$} & GHS & 1233 & 1826 & 1960 & 1970 & 2017 & 2017 & 2017 & 2003 & 2003 & 915 & \\
\hline & & TMA & 1208 & 2360 & 2380 & 2450 & 2550 & 2740 & 2560 & 2450 & 2410 & 1125 & \\
\hline & & Ratio & 1.02 & 0.77 & 0.82 & 0.82 & 0.79 & 0.74 & 0.79 & 0.82 & 0.83 & 0.81 & 0.82 \\
\hline & \multirow[t]{3}{*}{$1986-90$} & GHS & 1213 & 1744 & 1789 & 1795 & 1906 & 1906 & 1906 & 1710 & 1710 & 875 & \\
\hline & & TMA & 1587 & 2317 & 2150 & 2350 & 2450 & 2533 & 2483 & 1967 & 2133 & 1065 & \\
\hline & & Ratio & 0.76 & 0.75 & 0.83 & 0.76 & 0.78 & 0.75 & 0.77 & 0.87 & 0.80 & 0.82 & 0.79 \\
\hline & \multirow[t]{2}{*}{ 1991-95 } & GHS & 927 & 1666 & 1551 & 1551 & 1567 & 1567 & 1567 & 1479 & 1479 & 778 & \\
\hline & & Adjusted $^{3}$ & 1159 & 2083 & 1939 & 1939 & 1959 & 1959 & 1959 & 1849 & 1849 & $973^{4}$ & \\
\hline
\end{tabular}

${ }^{1}$ Adjusted by dividing GHS estimate by 0.75 .

Estimates are $1434,1090,874,715$ and 477 for ages $60-64,65-69,70-74,75-79,80+$

Adjusted by dividing GHS estimates by 0.80 .

${ }^{4}$ Estimates are $1583,1188,746,574$ and 325 for ages $60-64,65-69,70-74,75-79,80+$

adult per year for $1971-75,1976-80,1981-85$ and 1986-90. GHS estimates were lower by a factor averaging about 0.75 for men and 0.80 for women. Such a difference is expected because TMA, but not GHS, adjust data (upwards) to match known sales data and so correct for understatement of smoking. Also, excluding mainly handrolled cigarette consumption in the GHS estimation omits those who smoke mainly but not exclusively handrolled cigarettes included in the TMA data. As no age or time related patterns were seen in the GHS/TMA factors, 1991-95 data to include in CCTCC estimates were obtained by dividing GHS estimates by the factors of 0.75 or 0.80 , as is also shown in table 2 .

Table 3 gives updated CCTCC estimates for 1991-95 and also, for comparison, for 1981-85 and 1986-90. In men the estimates are declining at all ages, with the percentage reduction between 1981-85 and 1991-95 steeper at younger ages. In women, though relatively marked declines are seen at young ages, lesser declines are seen in middle age with increases seen at older ages.

An updated graphical display of the full CCTCC data will appear in LAIA factsheets and is not reproduced here.

\section{Discussion}

CCTCC was developed by $\operatorname{Todd}^{7}$ to be a simple index of lifetime tobacco exposure with some predictive value for risk of lung cancer and other chronic smoking associated diseases. Anyone using CCTCC should understand its possible limitations which include the following:

(1) CCTCC ignores the smoking of pipes, cigars or handrolled cigarettes.

(2) CCTCC assumes that exposure early and late in life are equally important in determining risk.

Table 3 Cumulative constant tar cigarette consumption (in thousands) by sex, age and period ${ }^{l}$

\begin{tabular}{|c|c|c|c|c|c|c|c|c|}
\hline \multirow[b]{2}{*}{ Age } & \multicolumn{4}{|l|}{ Men } & \multicolumn{4}{|l|}{ Women } \\
\hline & $1981-85$ & $1986-90$ & $1991-95$ & $\%$ change $^{2}$ & $1981-85$ & $1986-90$ & 1991-95 & $\%$ change $^{2}$ \\
\hline $15-19$ & 3 & 2 & 2 & -40.3 & 2 & 2 & 1 & -31.8 \\
\hline $20-24$ & 10 & 8 & 6 & -41.5 & 8 & 6 & 5 & -38.3 \\
\hline $25-29$ & 23 & 17 & 13 & -44.5 & 17 & 13 & 10 & -42.3 \\
\hline $30-34$ & 38 & 29 & 21 & -43.5 & 27 & 23 & 18 & -35.2 \\
\hline $35-39$ & 56 & 44 & 34 & -39.7 & 37 & 33 & 27 & -27.0 \\
\hline $40-44$ & 75 & 63 & 49 & -34.6 & 45 & 43 & 37 & -18.6 \\
\hline $45-49$ & 92 & 81 & 67 & -26.7 & 52 & 51 & 47 & -9.0 \\
\hline 50-54 & 113 & 98 & 86 & -23.7 & 62 & 57 & 55 & -10.8 \\
\hline $55-59$ & 140 & 118 & 102 & -27.2 & 74 & 67 & 61 & -17.9 \\
\hline $60-64$ & 163 & 145 & 122 & -25.0 & 78 & 79 & 71 & -9.1 \\
\hline $65-69$ & 179 & 167 & 149 & -17.2 & 75 & 81 & 82 & +9.4 \\
\hline $70-74$ & 194 & 183 & 169 & -12.9 & 67 & 77 & 73 & +23.7 \\
\hline $75-79$ & 206 & 197 & 185 & -10.2 & 57 & 69 & 78 & +37.2 \\
\hline $80-84$ & 213 & 208 & 199 & -6.7 & 47 & 58 & 70 & +49.6 \\
\hline
\end{tabular}

${ }^{1}$ For data for earlier periods see reference 4 .

${ }^{2}$ 1991-95 compared with 1981-85. 
(3) CCTCC may not reflect changes which occur in the relative distribution of heavy and light smokers if the underlying risk-response is non-linear.

(4) Early data had to be estimated by backward extrapolation (although as surveys go back 50 years this is less of a problem now than formerly).

(5) Data had to be estimated from two surveys - the TMA until 1990 and the GHS subsequently - although the relatively consistent ratios in table 2 and the relatively small contribution of 1991-95 data to total CCTCC estimates suggest this is of minor importance.

(6) Changes in tar levels are assumed to be independent of age and sex, however available data $^{2}$ suggest this may not be a major difficulty.

(7) There is some uncertainty over tar levels prior to 1965 . We used TMA data suggesting that SWAT was constant at $31.4 \mathrm{mg} / \mathrm{cig}$ before 1965. Wald et $a l,{ }^{8}$ based on chemical analyses conducted around 1980 of old cigarettes sent in by the public, claimed that SWAT declined before 1965. In fact, the pre-1965 SWAT levels they cited $(32.9,32.2,29.4$ and $30.4 \mathrm{mg} / \mathrm{cig}$ for 1934-40, 1941-47, 1948-54, and 1955-61, respectively) were close to the TMA figure of $31.4 \mathrm{mg} / \mathrm{cig}$, and their lower figure of 25.5 $\mathrm{mg} / \mathrm{cig}$ for 1962-68 was based on an unrepresentative sample of brands sold, predominantly towards the end of the period, when the TMA data also showed a marked decline (23.9 $\mathrm{mg} / \mathrm{cig}$ in 1968). The use of Wald's SWAT data would have little effect on CCTCC levels or trends in any case.

The most important problem with CCTCC may lie in using tar yield data, based on machine smoking under standard conditions, to index exposure to tar. Although it is reasonably clear that lower tar yields are associated with reduced mortality from lung cancer, ${ }^{9}$ and that smokers switching to lower tar brands do reduce average tar intake, ${ }^{10}{ }^{11}$ smokers do appear to "compensate" for reduced tar (and nicotine) delivery by modifying how they smoke. $^{12}$ It has been estimated that the reduction in tar intake is only about half the reduction predicted based on the published tar yields. $^{1011}$
In additional analyses to study effects of adjustment for compensation (data not shown), we recalculated CCTCC assuming either (1) that tar levels had not reduced since 1965 ("complete compensation") or (2) that tar levels had reduced by the square root of the observed decline in machine yields ("partial compensation"). The decline in CCTCC in men at all ages over the period 1981-85 to 1991-95 was confirmed under both assumptions. However, the decline in CCTCC in women was only really evident below the age of 40 in the complete compensation analysis and below the age of 45 in the partial compensation analysis, compared with below the age of 65 in the analyses in table 3 which ignore compensation.

We thank Pauline Wassell and Diane Morris for their careful typing of this paper. No financial support was received for this work.

1 Lee PN, Fry JS, Forey BA. Trends in England and Wales lung cancer, chronic obstructive pulmonary disease and emphysema death rates $1941-84$ and their relatio
trends in cigarette smoking. Thorax 1990;45:657-65.

2 Lee PN, ed. Statistics of smoking in the United Kingdom. Tobacco Research Council Research Paper I. 7th ed. London: Tobacco Research Council, 1976.

3 Wald N, Nicolaides-Bouman A, eds. UK smoking statistics. 2nd ed. London, Oxford, New York, Tokyo: Wolfson Institute of Preventive Medicine and OUP, 1991.

4 Lee PN, Fry JS, Forey BA. Estimating age, sex and period specific constant tar cigarette consumption in the UK (letter). Thorax 1993;48:679.

5 Lee PN, Fry JS, Forey BA. Estimation of age, sex and period specific constant tar cigarette consumption in the UK. 1993 available from P N Lee Statistics and Computing Ltd, 17 Cedar Road, Sutton, Surrey SM2 5DA, UK).

6 World Health Organisation. World Health Statistics Annual. Geneva: WHO, successive years.

7 Todd GF. Changes in smoking patterns in the UK. Occasional paper 1. London: Tobacco Research Council; 1975.

8 Wald N, Doll R, Copeland G. Trends in the tar, nicotine and carbon monoxide yields of UK cigarettes manufactured since 1934. BMF 1981;282:763-5.

9 Tang J-L, Morris JK, Wald NJ, et al. Mortality in relation to tar yield of cigarettes: a prospective study of four cohorts. tar yield of cigarettes: a

10 Stephen A, Frost C, Thompson S, et al. Estimating the extent of compensatory smoking. In: Wald N, Froggatt P, eds. Nicotine, smoking and the low tar programme. Oxford: Oxford University Press, 1989: 100-15.

11 Pritchard WS, Robinson JH. Examining the relation between usual-brand nicotine yield, blood cotinine concentration and the nicotine "compensation" hypothesis. Psychopharmacology 1996;124:282-4.

12 Russell MAH, Jarvis MJ, Feyerabend C, et al. Reduction of tar, nicotine and carbon monoxide intake in low tar smokers. $\mathcal{F}$ Epidemiol Community Health 1986;40:80-5. 